\title{
Analisis Big Data Geomagnetik Dengan Metode Diferensiasi Sebagai Prekursor Gempa Lombok Tahun 2018
}

\author{
Geomagnetic Big Data Analysis Using Differentiation Method as Precursor \\ of The 2018 Lombok Earthquake
}

\author{
Dwi Ratnasari", Helmy Amalia Ariesta, Teti Zubaidah, Bulkis Kanata, \\ Made Sutha Yadnya, Paniran, Supriyatna \\ Jurusan Teknik Elektro, Fakultas Teknik, Universitas Mataram \\ *Corresponding Author Email: dwi.ratnasari@unram.ac.id
}

Manuscript received: 08-12-2020. Accepted: 26-10-2021

\begin{abstract}
ABSTRAK
Lombok merupakan wilayah dengan anomali geomagnetik tertinggi di Indonesia (Zubaidah et al., 2014). Sejak akhir bulan Juli hingga akhir bulan Agustus 2018, Lombok mengalami kejadian gempa beruntun yang cukup besar. Identifikasi sinyal geomagnetik khususnya pada spektrum Ultra Low Frequency (ULF) dapat digunakan sebagai prekursor gempa (Saroso, 2010). Intermagnet IAGA (International Aeronomy Geomagnetic Assocoation) adalah jaringan stasiun observatori geogmagnetik internasional yang memiliki data geomagnetik dunia dalam ukuran besar. Analisis big data menjadi sangat penting karena dibutuhkan informasi yang sangat besar dalam mitigasi bencana. Penelitian ini menggunakan data geomagnetik per detik selama 24 jam mulai 28 Agustus sampai 30November 2018 yang diambil dari Kakadu (KDU) Australiadan Stasiun Nurul Bayan (NRB) Lombok.Metode analisis yang digunakan adalah Diferensiasi dengan menghitung nilai $\mathrm{F}$ (medan magnet total) untuk KDU dan NRB, kemudian mencari selisihnya dan menganalisis polanya. Hasilnya ditemukan ada fenomena anomali medan magnet Bumi di Nurul Bayan Lombok yang terdeteksi selama 17 hari selama Oktober 2018.
\end{abstract}

Kata kunci: geomagnetik; diferensiasi; bayan; kakadu; prekursor; gempa

\begin{abstract}
Lombok is an area with the highest geomagnetic anomaly in Indonesia (Zubaidah et al., 2014). From the end of July to the end of August 2018, Lombok experienced a series of fairly large earthquakes. Identification of geomagnetic signals, especially in the Ultra Low Frequency (ULF) spectrum, can be used as earthquake precursors (Saroso, 2010). Intermagnet IAGA (International Aeronomy Geomagnetic Association) is a network of international geomagnetic observatory stations that have large world geomagnetic data. Big data analysis is very important because very large information is needed in disaster mitigation. This study uses geomagnetic data per second for 24 hours from 28 August to 30 November 2018 taken from Kakadu (KDU) Australia and Nurul Bayan Station (NRB) Lombok. The analytical method used is Differentiation by calculating the $\mathrm{F}$ value (total magnetic field) for KDU and NRB, then look for the difference and analyze the pattern. The results found that
\end{abstract}


there was an anomaly phenomenon of the Earth's magnetic field in Nurul Bayan Lombok which was detected for 17 days during October 2018.

Keyword: geomagnetic; differentiation; bayan; kakadu; precursor; earthquake

\section{PENDAHULUAN}

Lombok sebagai wilayah dengan anomali geomagnetik intensitas tertinggi di Indonesia (Zubaidah et al., 2014). Tahun 2018, Lombok mengalami gempa beruntun yang cukup besar. Universitas Mataram memiliki Pusat Unggulan Iptek (PUI) Geomagnetik yang fokus pada mitigasi bencana dan konservasi lingkungan.Pada bulan November 2019 Lombok dipilih sebagai tempat untuk mendeklarasikan terbentuknya KOGNAS (Konsorsium Geomagnetik Nasional) dan menjadi ikon geomagnet nasional.Jaringan Intermagnet IAGA (International Aeronomy Geomagnetic Assocoation) adalah jaringan stasiun observatori geogmagnetik internasional yang memiliki data geomagnetik dunia dalam ukuran besar. Analisis big data menjadi sangat penting karena untuk melakukan mitigasi bencana membutuhkan informasi yang sangat besar. Permasalahan yang terjadi adalah masih sedikitnya penelitian terkait data geomagnetik Lombok tahun 2018.

Penelitian geomagnet untuk prediksi terjadinya gempa di daerah patahan pulau Lombok telah dimulai oleh KPBI EMTECH (Kelompok Peneliti Bidang Ilmu Electromagnetic Technology and Environmental Conservation for Humanity) sejak tahun 2006 (Zubaidah et al., 2006). Penelitian terhadap gempa yang terjadi di tiga regional berbeda yaitu Jepang, Amerika, dan Indonesia dengan menggunakan metode Diferensiasi dan Moving Average dilakukan pada tahun 2000-2011. Untuk regional Indonesia terlihat jelas penurunan level pada sinyal geomagnetik, dan kenaikan level pada sinyal Diferensiasi, terutama sebelum gempa 9.1 SR di Sumatera dengan anomali lebih dari $200 \mathrm{nT}$ selama beberapa hari sebelum gempa (Zubaidah et al., 2013). Penelitian terhadap empat gempa besar dengan amplitudo diatas 7SR yang terjadi di regional Jepang tahun 2000-2011, menggunakan prosedur Diferensiasi dan Moving. Hasil pengolahan sinyal dengan menggunakan metode Diferensiasi menunjukkan adanya fluktuasi geomagnetik dengan magnitude tinggi yang terlihat dari sejak 3 bulan sampai 1 bulan sebelum kejadian gempa, yang kemungkinan dapat dijadikan sebagai prekursor kejadian gempa bumi besar (Kanata et al., 2013). Tercatat Total kejadian gempa di Lombok dan sekitarnya dari tahun 1900 sampai 2014 adalah 2081 kejadian dengan klasifikasi untuk gempa dengan magnitud 4-4.9 terdapat 1709 kejadian, untuk gempa dengan magnitud 5-5.9 terdapat 336 kejadian, untuk gempa dengan magnitud 6-8 terdapat 36 kejadian untuk gempa. Gempa-gempa tersebut merupakan gempa-gempa dangkal (kedalaman $<40 \mathrm{~km}$ ) yang berpotensi menimbulkan bencana (Kinasih et al., 2014).

Terdapat gejala anomali sinyal ULF dan fenomena penurunan signifikan medan magnet Bumi di wilayah Lombok yang terdeteksi selama dua tahun terakhir sebelum kejadian gempa 2018. Identifikasi sinyal geomagnetik khususnya pada spektrum Ultra Low Frequency (ULF) dapat digunakan sebagai prekursor gempa (Saroso, 2010). Metode analisis yang digunakan adalah Diferensiasi dengan menghitung nilai $F$ (medan magnet total) untuk stasiun Nurul Bayan (NRB) Lombok dan observatorium Kakadu (KDU) Australia, kemudian mencari 
selisihnya dan menganalisis polanya. Hasil yang didapat dari penelitian ini adalah danya fenomena anomali geomagnetik di wilayah Nurul Bayan Lombok yang terdeteksi pada bulan Oktober 2018. Anomali sinyal ULF ini diperkirakan sebagai pertanda sebelum kejadian gempa. Dengan mengetahui karakteristik gempa bisa dijadikan sebagai kajian strategis untuk membangun sistem peringatan dini gempa bumi atau Earthquake Early Warning System (EEWS) Pulau Lombok dalam upaya mitigasi bencana berikutnya.

\section{BAHAN DAN METODE}

\section{Bahan}

Dalam penelitian ini menggunakan perangkat keras berupa Laptop Dell Vostro Intel Core i5 processor. Sedangkan perangkat lunak yang digunakan adalah Matlab, Windows 10 Pro, dan Microsoft Office 365 Original. Untuk data yang dianalisis adalah data geomagnetik dari Observatorium Geomagnetik Kakadu (KDU) Australia yang telah terintegrasi dalam jaringan Intermagnet IAGA dan Stasiun Geomagnetik Nurul Bayan (NRB) Lombok Utara milik Universitas Mataram.

Data geomagnetik yang digunakan adalah per detik selama 24 jam dari tanggal 28 Agustus - 30 November 2018. Data primer diambil dari Stasiun Geomagnetik Nurul Bayan, Dusun Telaga Banyak, Desa Anyar, Kecamatan Bayan, Kabupaten Lombok Utara, Provinsi Nusa Tenggara Barat (Gambar 1.a). Sedangkan data sekunder diambil dari Intermagnet IAGA observatorium Kakadu Australia (Gambar 1.b).Data telah direpresentasikan dalam bentuk tabel yang disimpan dengan format file txt.Total data yang digunakan pada penelitian ini adalah 16.243.200 records.

a

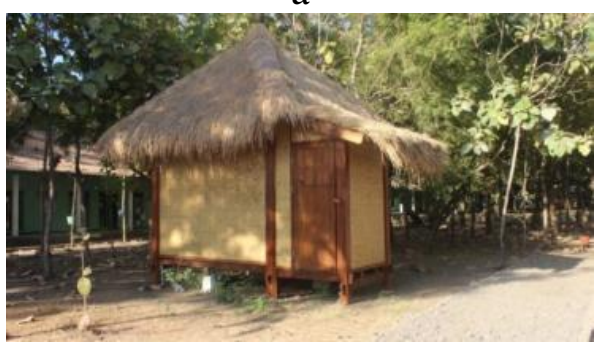

b

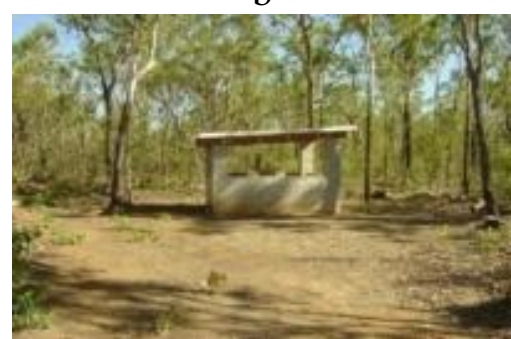

Gambar 1. (a) Stasiun Nurul Bayan Lombok (b) Observatorium Kakadu Australia (www.intermagnet.org)

\section{Sintesis tahap 1}

Agar penelitian ini dapat dilakukan dengan baik dan terstruktur maka dibuat alur penelitian yang akan menjelaskan langkah-langkah selama penelitian untuk mendapatkan hasil yang sesuai dengan tujuan penelitian ini. Pada tahap awal penelitian dimulai dengan pengumpulan data geomagnetik. Tahap kedua yaitu studi literatur tentang big data geomagnetik, metode diferensiasi, interpolasi, dan algoritma data tapis. Studi literatur diperoleh dari berbagai sumber seperti buku, jurnal, artikel, dan situs web.Tahap selanjutnya merupakan pengembangan sistem sebagai implementasi dari analisis big data geomagnetik dengan menggunakan metode diferensiasi. Pengujian sistem dilakukan sesuai dengan 
ketentuan skenario pengujian. Jika sistem belum melakukan pengujian terhadap semua skenario pengujian, maka akan kembali terhadap proses pembangunan sistem, untuk mengetahui memastikan semua skenario pengujian terpenuhi, apabila sistem telah berjalan untuk semua skenario pengujian, maka akan dilanjutkan ke tahap berikutnya.Pada tahap akhir dari penelitian ini akan dibuatkan laporan sebagai dokumentasi dari kegiatan penelitian. Adapun diagram alir penelitian dapat dilihat pada Gambar 2.

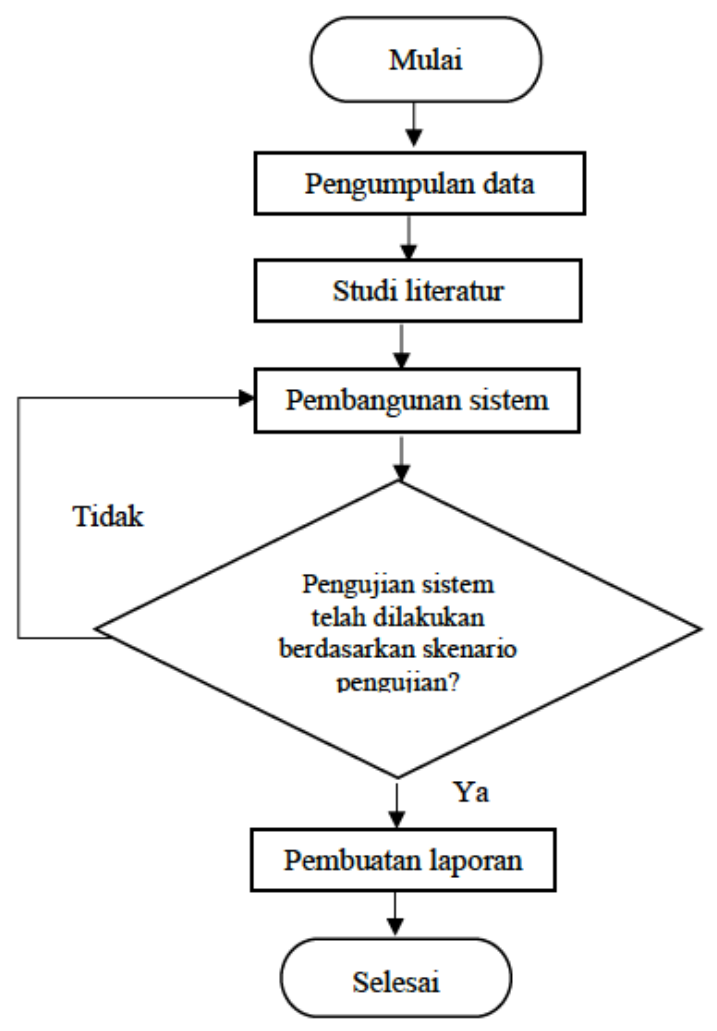

Gambar 2. Diagram alir penelitian.

\section{Sintesis tahap 2}

Pada tahapan ini diawali dengan input data NRB sebagai $\mathrm{Y}$ dan KDU sebagai $\mathrm{X}$, kemudian membuat folder F dan F1. Selanjutnya mengecek banyak data KDU dan NRB yaitu 86.400 per hari. Saat kurang dari 86.400 , maka dilakukan interpolasi. Interpolasi adalah proses "menebak" nilai data dengan memperhatikan data lain yang ada. Interpolasi merupakan teknik untuk mencari nilai suatu variabel yang hilang pada rentang data yang diketahui. Data lain yang kita miliki seringkali memiliki sejumlah pola. Pola yang terbentuk dapat berupa polinomial atau mengelompok. Tiap pola akan memiliki metode pendekatan yang berbeda-beda. Terdapat kemungkinan tak terbatas dari pola data tersebut. Penilaian profesional atau ahli diperlukan untuk menentukan metode mana yang sesuai berdasarkan riwayat penelitian atau pekerjaan yang pernah dilakukan sebelumnya (Howard, 2017). Pada penelitian ini, metode interpolasi digunakan untuk mengisi nilai medan magnetik total yang kosong pada data geomagnetik (Khairunnas et al., 2020). Metode interpolasi banyak digunakan untuk mengisi kekosongan pada data time series karena memiliki performa yang bagus dibandingkan dengan metode ekstrapolasi (Mathieu et al., 2017). 
Berikutnya adalah mengecek data apakah ada yang nilainya 99999? Saat ada data yang nilainya 99999, maka dijadikan $\mathrm{NaN}$ pada dataKDU dan NRB. Kemudian mencari diferensiasi data KDU dengan data NRB yang output hasilnya menjadi F. Berikut ini adalah persamaan untuk melakukan prosedur diferensiasi.

Dimana,

$$
\Delta \text { Diff }=F_{O b s 1}-F_{O b s 2}
$$

$\mathrm{F}_{\mathrm{Obs} 1}=$ Nilai medan magnet total Observatorium 1 (KDU)

$\mathrm{F}_{\mathrm{Obs} 2}=$ Nilai medan magnet total Observatorium $2(\mathrm{NRB})$

$\Delta$ Diff $=$ Nilai Diferensiasi $($ selisih F $)$

Selanjutnya menyimpan data X, Y, dan F, dimana data ini merupakan data yang akan diproses ke tapis. Terakhir adalah menampilkan grafik. Adapun diagram alir pengembangan sistem dapat dilihat pada Gambar 3.

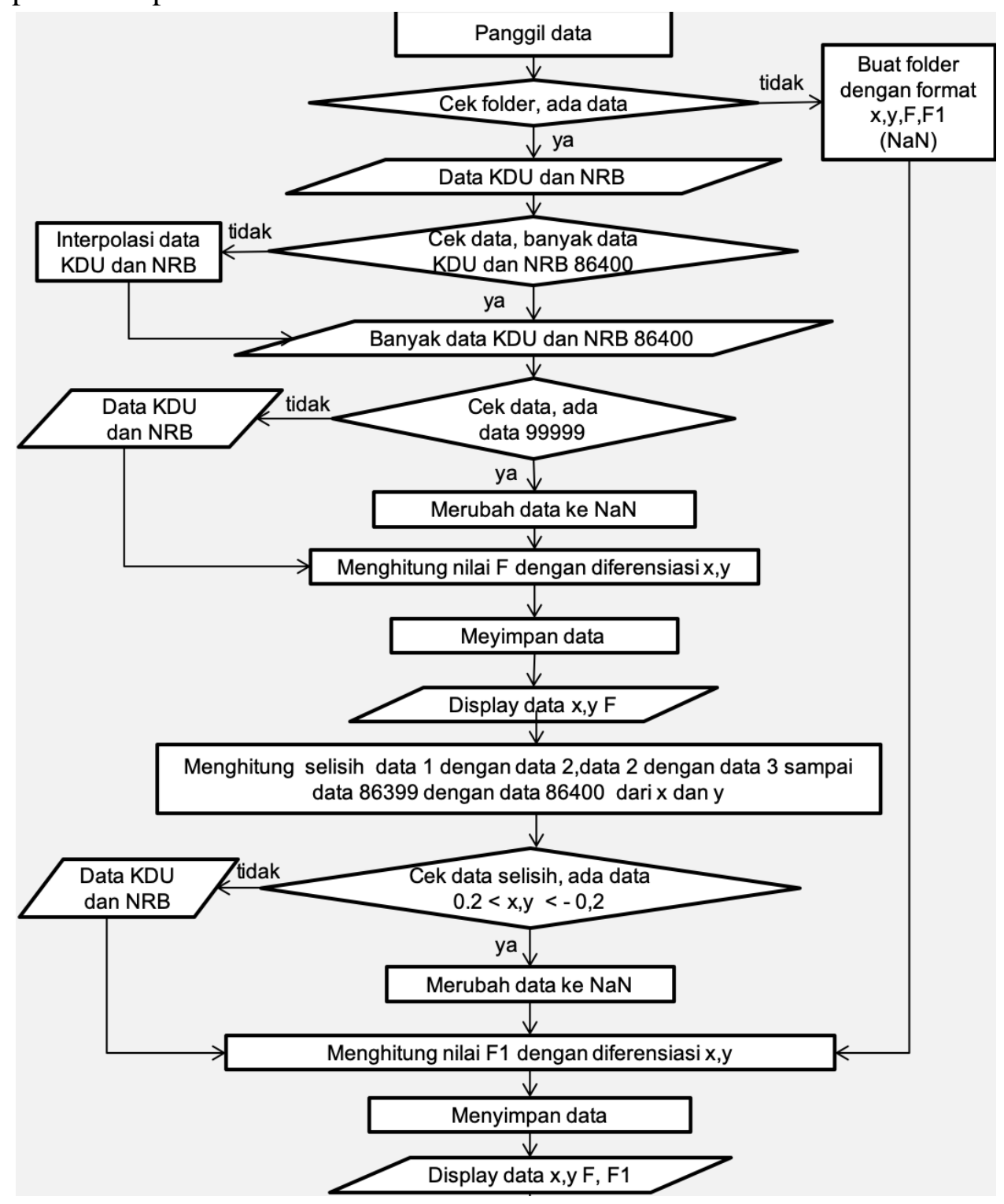

Gambar 3. Diagram alir pengembangan sistem. 


\section{Karaktersisasi data}

Pada penelitian ini data primer medan geomagnetik yang digunakan diperoleh dari instrumen fluxgate magnetometer yang dipasang oleh BMKG di Stasiun Geomagnetik Nurul Bayan (Gambar 4). Dalam hal ini dikelola oleh tim PUI Geomagnetik Universitas Mataram. Stasiun NRB mulai dioperasikan sejak April 2018, berlokasi di pesantren Nurul Bayan, Kabupaten Lombok Utara. Pada awal peresmiannya, stasiun NRB hanya dioperasikan dengan alat ukur skalar, tetapi setelah gempa Lombok 2018, pada Agustus 2018 dipasang instrumen tambahan yaitu fluxgate magnetometeryang berfungsi sebagai variometer untuk mengukur nilai variasi dari vektor dalam 3 sumbu $(\mathrm{X}, \mathrm{Y}, \mathrm{Z})$ yang merupakan komponen dari data geomagnetik.
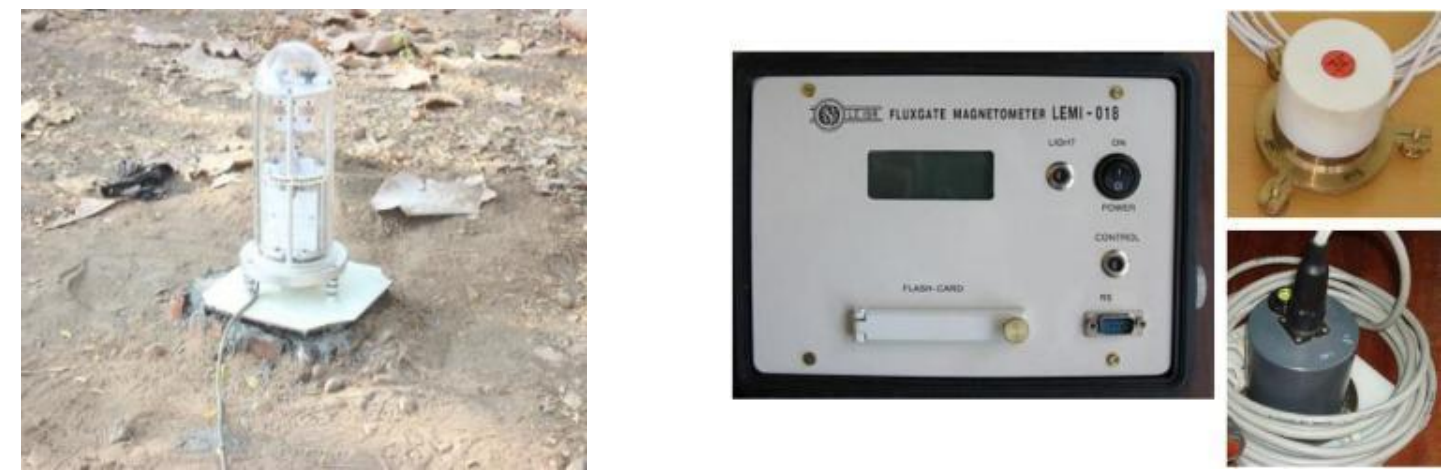

Gambar 4.Fluxgatemagnetometer di stasiun NRB.

Variometer merupakan suatu alat yang berfungsi untuk merekam nilai variasi tiap komponen medan magnetik bumi. Dalam hal ini komponen medan geomagnetik terdiri X, Y, Z. Di mana komponen-komponen tersebut menunjukkan koordinat geografis dalam satuan nano tesla (nT). Di mana X menunjukkan arah utara, Y menunjukkan arah timur dan $\mathrm{Z}$ selatan. Untuk keperluan penentuan prekursor gempa bumi, tidak hanya menggunakan nilai dari variasi medan geomagnetik melainkan harus menggunakan komponen tambahan yaitu F. Dimana F menyimbolkan nilai dari medan magnet total. Untuk mencari nilai medan magnet total dapat dihitung dengan menggunakan rumus pada Persamaan 2.

Dimana,

$$
F=\sqrt{(\Sigma \mathrm{X})^{2}+(\Sigma \mathrm{Y})^{2}+(\Sigma \mathrm{Z})^{2}}
$$

$\Sigma X$ menunjukkan jumlah nilai variasi $\mathrm{X}$ dan baseline $\mathrm{X}=37735,55 \mathrm{nT}$

$\Sigma Y$ menunjukkan jumlah nilai variasi $\mathrm{Y}$ dan baseline $\mathrm{Y}=800,33 \mathrm{nT}$

$\Sigma Z$ menunjukkan jumlah nilai variasi $\mathrm{Z}$ dan baseline $\mathrm{Z}=-24208,21 \mathrm{nT}$

Nilai dasar(baseline) dari setiap komponen medan magnet bumi X, Y, dan $\mathrm{Z}$ merupakan nilai standar dari International Geomagnetic Reference Field (IGRF) yang ditetapkan oleh IAGABaseline ini akan terus-menerus dipantau sebagai monitoring dalam proses dinamika perubahan nilai medan magnet bumi. Contoh data geomagnetik untuk 
komponen X, Y, Z yang terekam pada variometer di stasiun Nurul Bayan dapat dilihat pada

\section{Gambar 5.}

a

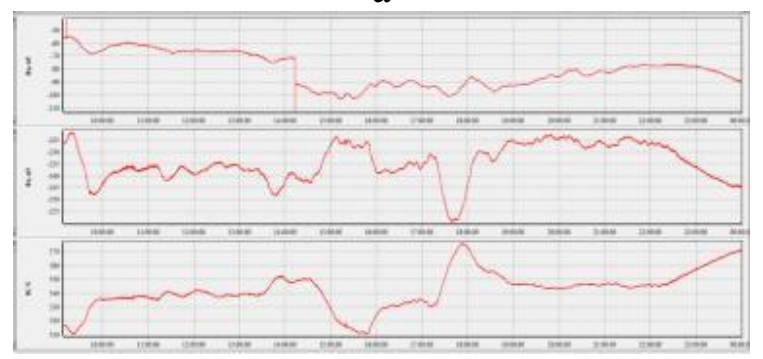

b

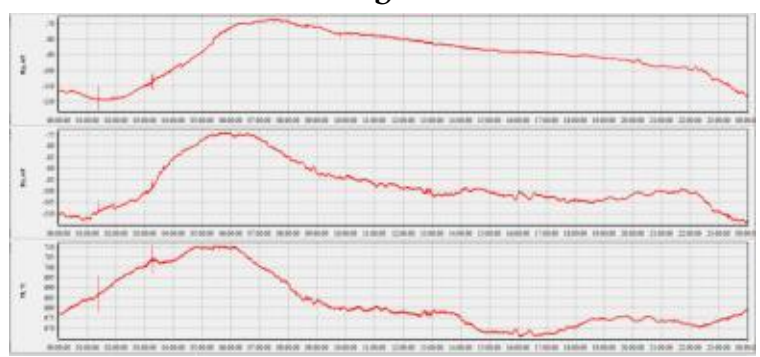

Gambar 5. Data geomagnetik (a) 27 Agustus 2018 (b) 29 Oktober 2018.

Diantara contoh bentuk anomali medan geomagnetik yaitu terdapat fluktuasi sinyal geomganetik dan frekuensi ganda. Selain itu, nilai medan geomagnetik total cenderung rendah ketika terjadi gempa bumi atau ketika jarak waktu kejadian gempa bumi terdekat terjadi. Contoh representasi data geomagnetik dalam format file txt dapat dilihat pada Tabel 1.

Tabel. 1. Datasetfile txt darirekamanvariometer.

\begin{tabular}{ccccccc}
\hline Waktu & TF & Y & Z & TE & X & Kualitas \\
\hline 20180831000000 & -62.70 & -89.57 & -22.948 & 00.00 & 595.76 ANFL & 99 \\
20180831000001 & 162.64 & -89.57 & -22.942 & 00.00 & 595.70 ANFL & 99 \\
20180901000000 & -74.75 & -89.76 & -22.930 & 00.00 & 595.38 ANFL & 99 \\
20180831000000 & 142.00 & -89.88 & -22.923 & 00.00 & 595.76 ANFL & 99 \\
20180831000001 & -65.54 & -89.44 & -22.930 & 00.00 & 595.70 ANFL & 99 \\
20180901000000 & 161.06 & -89.57 & -22.942 & 00.00 & 595.76 ANFL & 99 \\
\hline
\end{tabular}

\section{Uji peforma}

Pada tahap ini pengujiannya menggunakan tapis data. Algoritma yang digunakan untuk mencari selisih dari data 1dengan data 2, data 2 dengan data 3, sampai data 86.399 dengan data 86.400 dari data X dan Y. Kemudian mengecek hasil selisih dari data X dan Y.Apabila selisihnya >0.2 dan <-0.2 maka maka data $X$ dan $Y$ diuabah nilainya menjadi NaN, sebab nilai maksimum selisih tiap data yaitu harga mutlak 0.2. Selanjutnya adalah menghitung diferensiasi data F KDU dengan data F NRB yang outputnya menjadi F1. Terakhir adalah menyimpan data X, Y,F, dan F1.

\section{Hasil sintesis}

\section{HASIL DAN PEMBAHASAN}

Data geomagnetik yang terekam pada variometer mencatat dari jam 00.00 waktu UTC (Universal Time Coordinated). Data tersebut direkam perdetik, sehingga jumlah dataset terdiri dari 86.400 records data perharinya di satu stasiun/observatorium. Perbedaan waktu UTC dan WITA (Waktu Indonesia Tengah) mencapai 8 jam. Sedangkan perbedaan waktu ITC dan Kakadu, Australia sekitar 8.5 jam. Data yang dianalisis adalah hasil tapis dengan mengubah data pencilan (outlier) menjadi NaN. Outlier adalah suatu data yang menyimpang 
dari sekumpulan data yang lain. Pencilan pada data geomagnetik dikarenakan adanya aktivitas/gangguan makhluk hidup di sekitar alat sehingga menginterferensi hasil penangkapan sinyal dan keberadaan logam yang berada disekitar alat yang sangat mempengaruhi medan magnet bumi.

Hasil Diferensiasi F KDU - F NRB memiliki dua kategori yaitu normal jika hasilnya diantara 700 - 750 nT dan anomali jika di atas atau di bawah nilai normal. Berikut ini adalah data anomali yang ditemukan dalam selang waktu tanggal 28 Agustus - 30 November 2018.

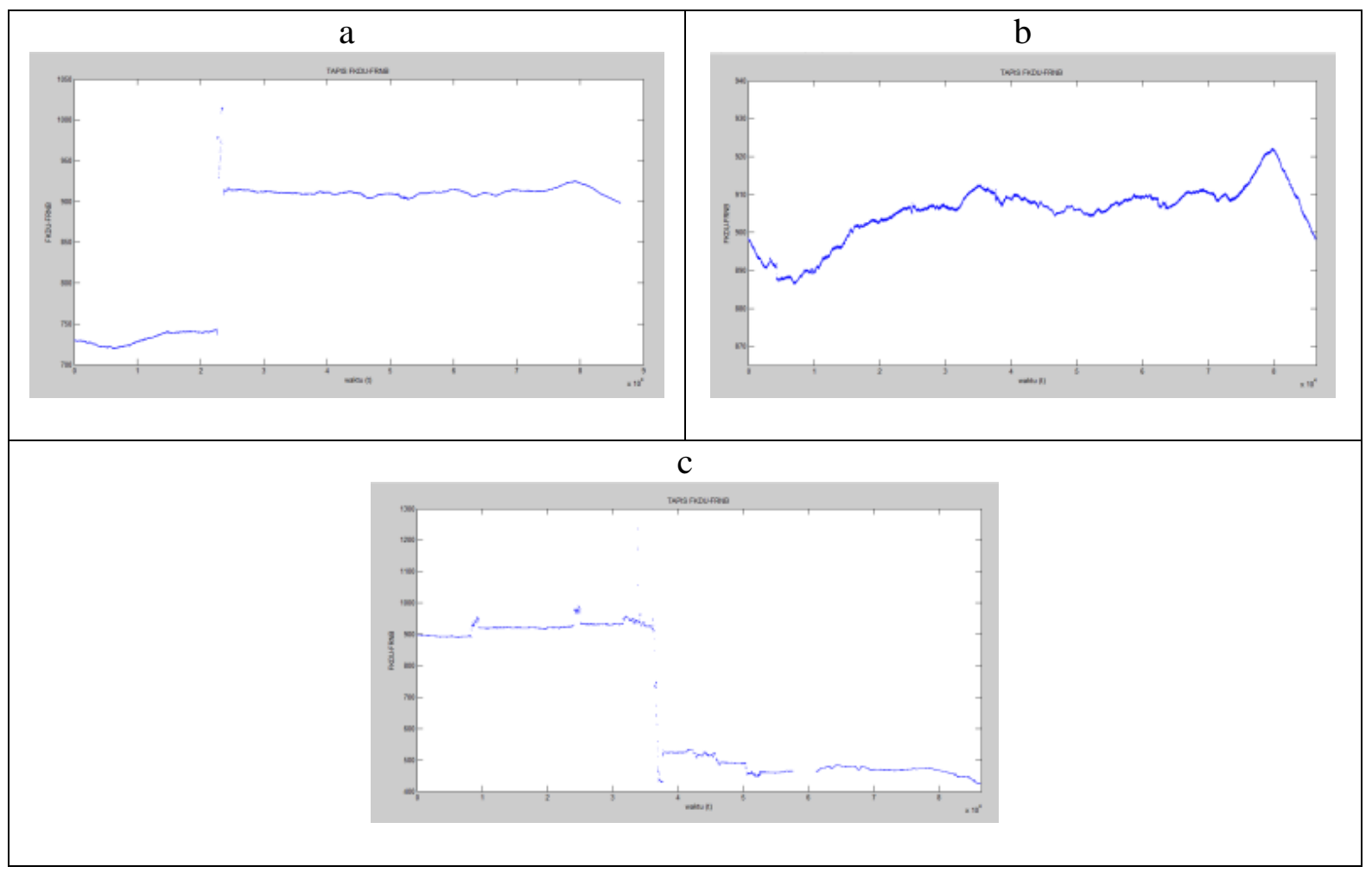

Gambar 6. Nilai F per hari (a) 11 Oktober 2018, (b) 12 Oktober 2018, (c) 13 Oktober 2018

Dari Gambar 6. dapat diketahui bahwa F KDU - F NRB = -+ 900 nT pada tanggal 11 - 13 Oktober 2018. Ini artinya medan magnet total di Stasiun Nurul Bayan mengalami penurunan yang signifikan sekitar 200 nT (selama 3 hari). Biasanya ini menandakan kejadian sebelum gempa.

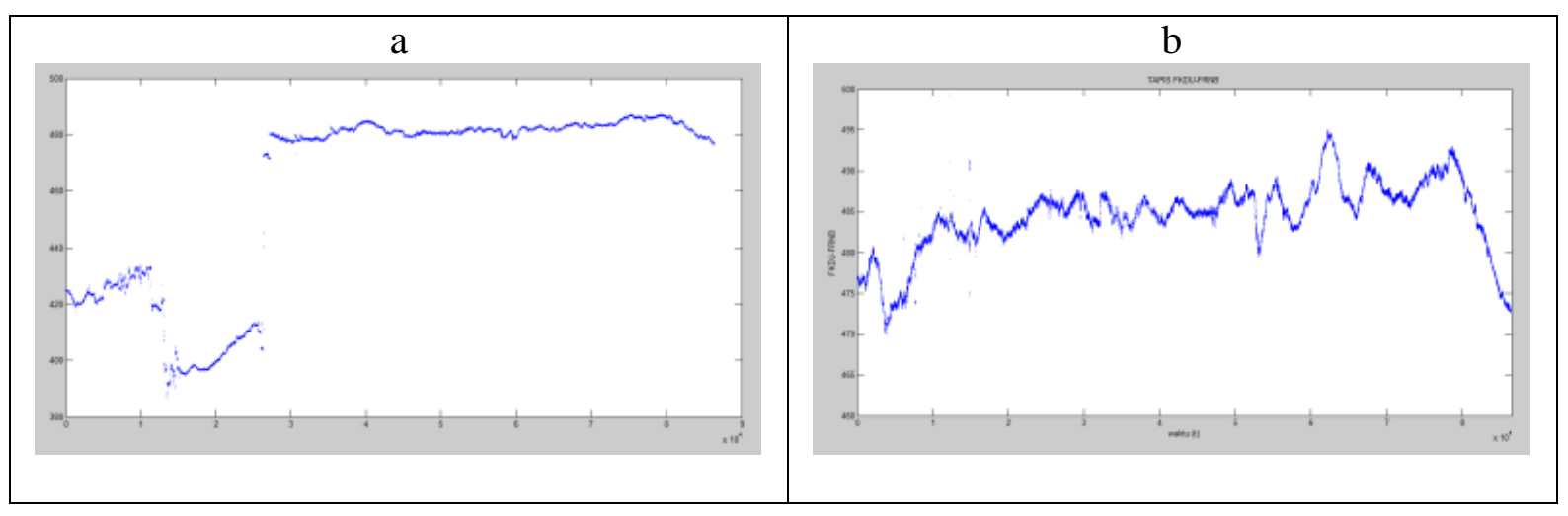




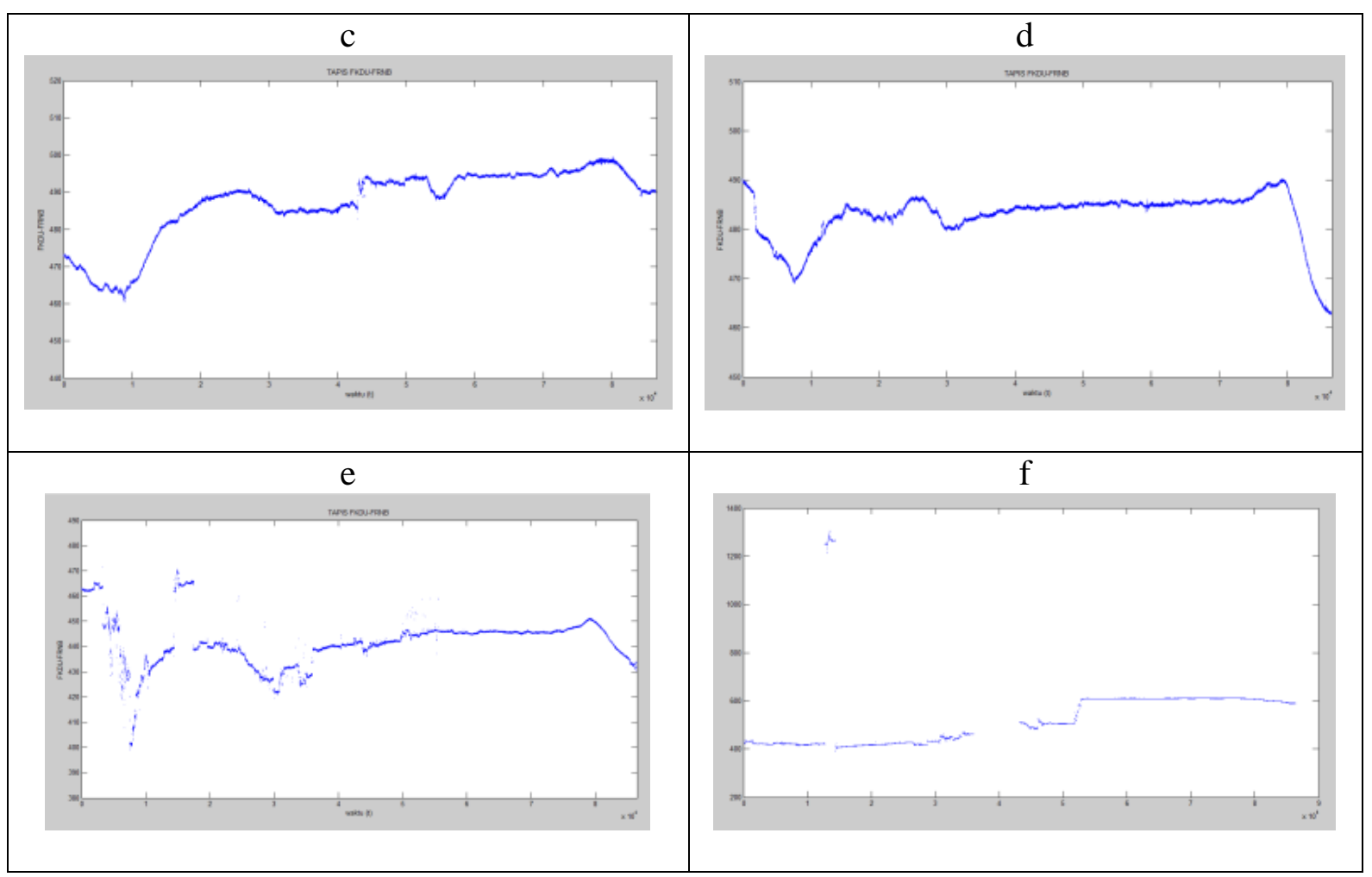

Gambar 7. Nilai F per hari (a) 14 Oktober 2018, (b) 15 Oktober 2018, (c) 16 Oktober 2018, (d) 17 Oktober 2018, (e) 18 Oktober 2018, (f) 19 Oktober 2018

Dari Gambar 7. dapat diketahui bahwa F KDU - F NRB = -+ 400 nT pada tanggal 14 19 Oktober 2018. Ini artinya medan magnet total di Stasiun Nurul Bayan mengalami kenaikan yang signifikan sekitar 300 nT (selama 6 hari). Biasanya ini menandakan kejadian gempa, yaitu bumi melepaskan energinya yang disertai dengan kenaikan medan magnetnya.

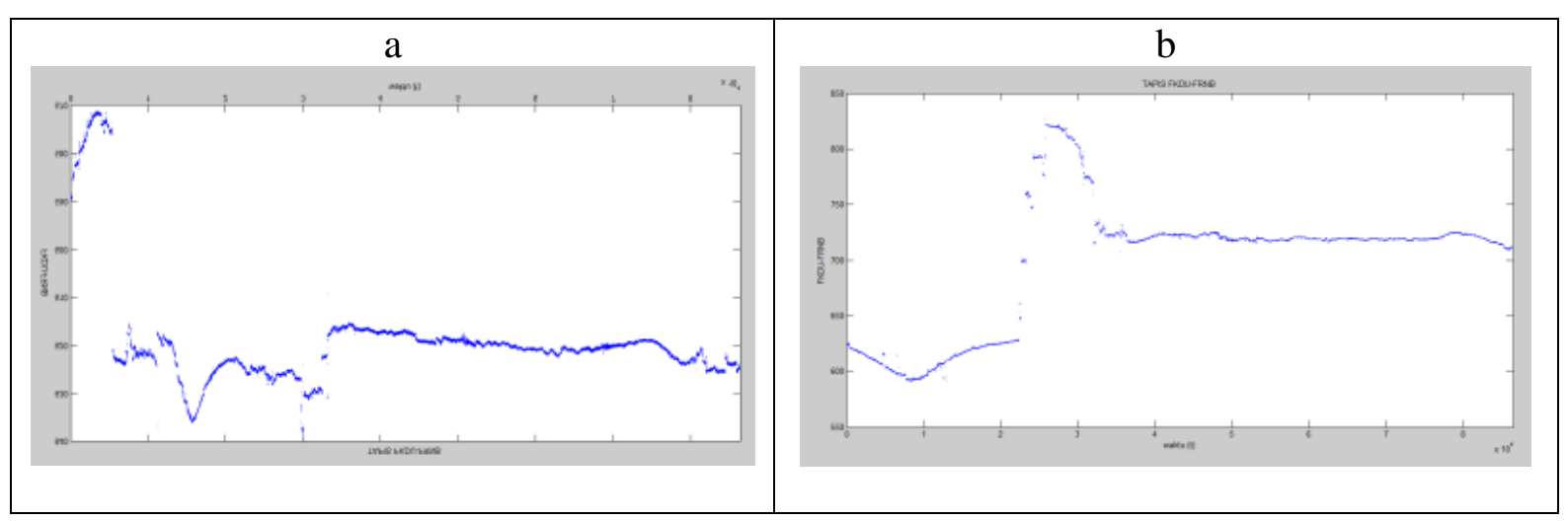




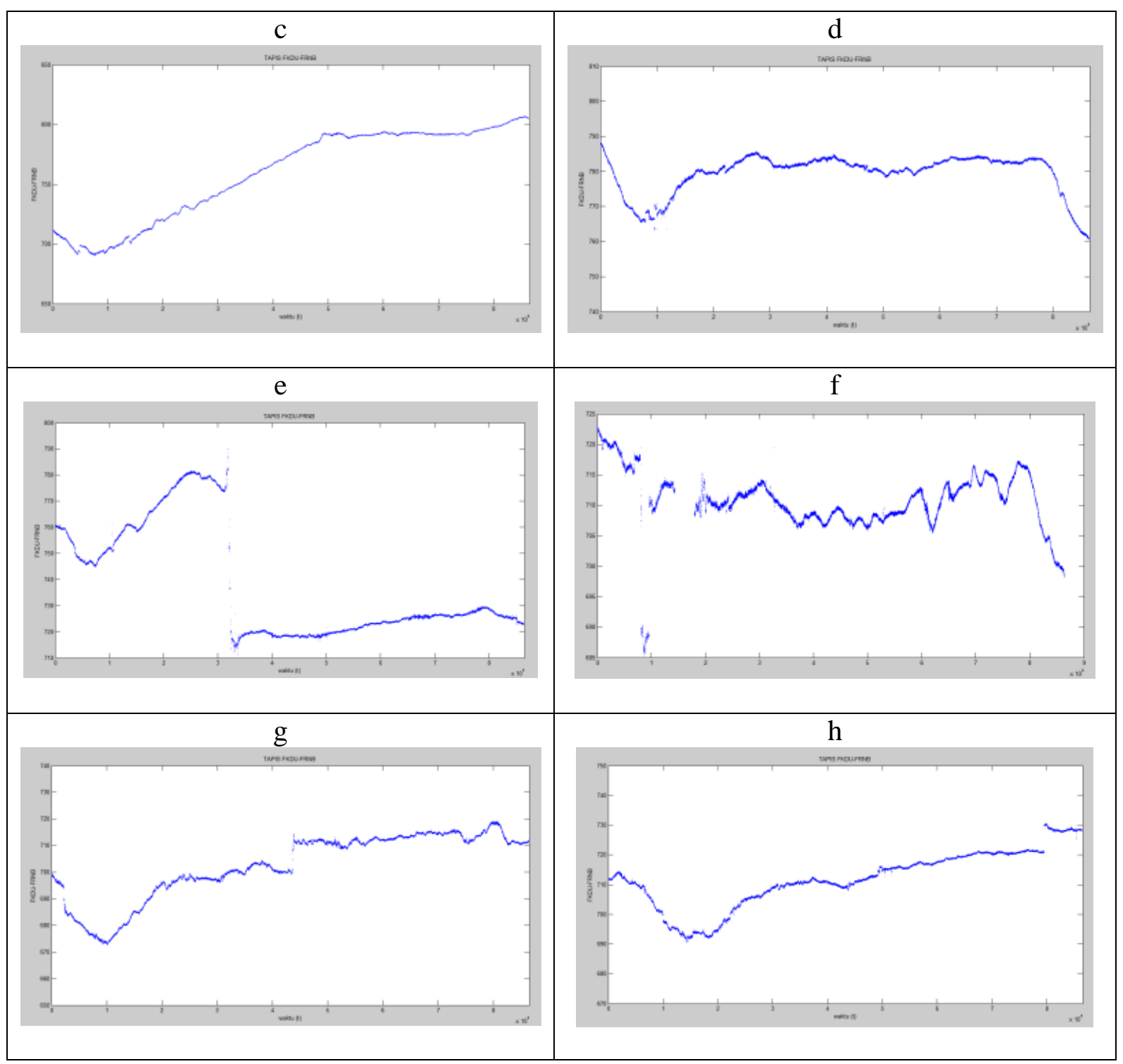

Gambar 8. Nilai F per hari (a) 20 Oktober 2018, (b) 21 Oktober 2018, (c) 22 Oktober 2018, (d) 23 Oktober 2018, (e) 24 Oktober 2018, (f) 25 Oktober 2018, (g) 26 Oktober 2018, (h) 27 Oktober 2018

Dari Gambar 8. dapat diketahui bahwa F KDU - F NRB = -+ 400-800 nT pada tanggal 20 - 27 Oktober 2018. Ini artinya medan magnet total di Stasiun Nurul Bayan masih belum stabil di nilai 700 - $750 \mathrm{nT}$ (selama 8 hari). Biasanya ini menandakan kejadian setelah gempa, yaitu medan magnet bumi perlu waktu untuk menyesuaikan kembali dengan kondisi normal.

\section{Efek perubahan nilai outlier}

Deteksi outlier dilakukan sesuai dengan langkah-langkah pada Gambar 3. Deteksi outlier dilakukan pada tiap data harian sebelum dihitung nilai medan magnet total (F). Pada penelitian ini record data yang termasuk outlier tidak akan dihilangkan/dihapus, melainkan akan diubah menjadi $\mathrm{NaN}$, kemudian nilai $\mathrm{NaN}$ tersebut akan diisi dengan metode interpolasi 
(Khairunnas et al., 2020). Pada Gambar 9. menunjukkan nilai F sebagai outlier dengan menggunakan nilai pagar dalam dan pagar luar sebagai acuan.

\begin{tabular}{rrrrr} 
& datetime & F & F1 & F2 \\
\hline 12894 & 20181003033756 & 45484.03 & $\mathrm{NaN}$ & 45483.59 \\
12895 & 20181003033757 & 45484.36 & $\mathrm{NaN}$ & 45483.41 \\
12896 & 20181003033758 & 45484.55 & $\mathrm{NaN}$ & 45483.24 \\
12897 & 20181003033759 & 45484.94 & $\mathrm{NaN}$ & 45483.07 \\
12898 & 20181003033800 & 45485.02 & $\mathrm{NaN}$ & 45482.89 \\
30171 & 20181003083451 & 45451.96 & $\mathrm{NaN}$ & 45453.02 \\
30172 & 20181003083452 & 45451.64 & $\mathrm{NaN}$ & 45453.01 \\
30173 & 20181003083453 & 45451.64 & $\mathrm{NaN}$ & 45452.99 \\
30174 & 20181003083454 & 45452.09 & $\mathrm{NaN}$ & 45452.98 \\
30268 & 20181003083630 & 45452.35 & $\mathrm{NaN}$ & 45453.64 \\
30294 & 20181003083656 & 45452.36 & $\mathrm{NaN}$ & 45453.32
\end{tabular}

Gambar 9. Contoh deteksi outlier dan perubahan nilainya.

Sedangkan deteksi outlier untuk data tapis seperti ditunjukkan pada Gambar 10.,Gambar 11., dan Gambar 12. berikut ini.

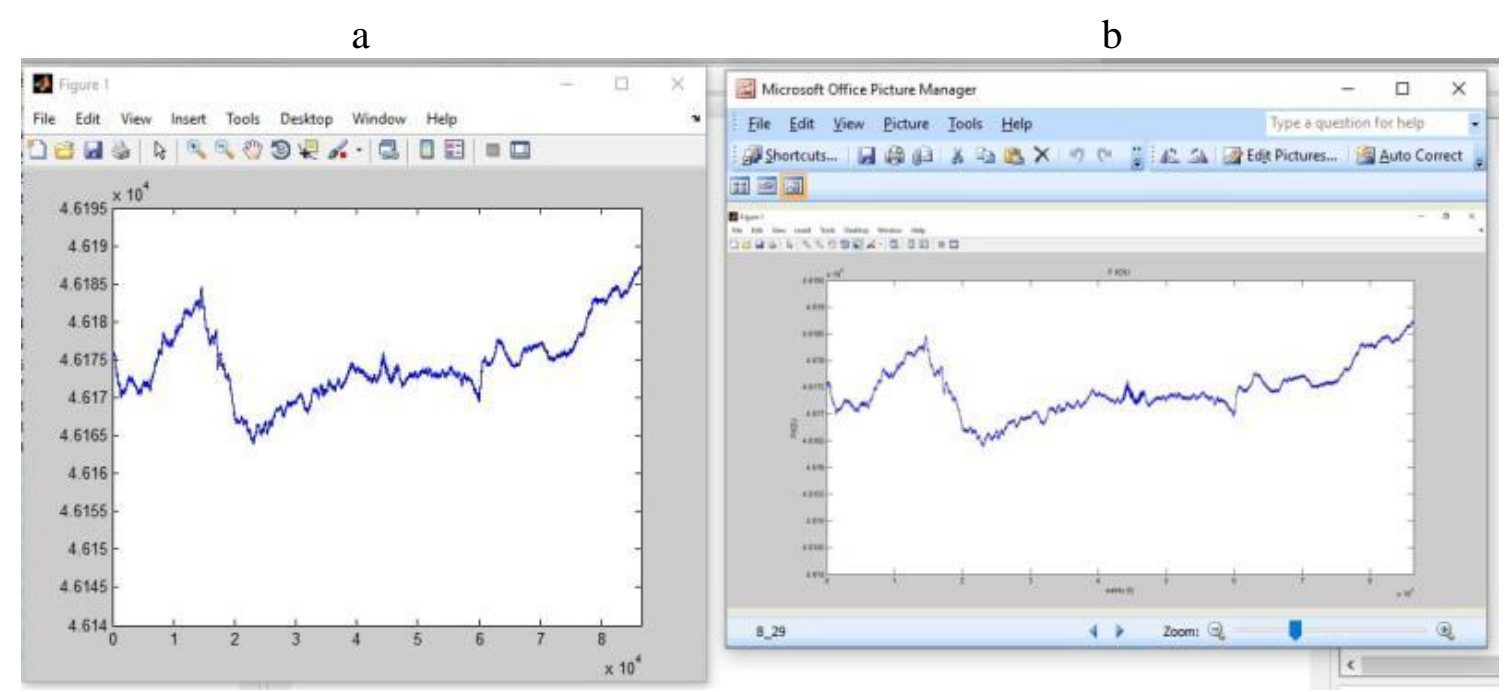

Gambar 10. Grafik F KDU

Gambar 10. menunjukkan data medan magnet total (F) di Observatorium Kakadu Australia tanggal 29 Agustus 2018, dimana (a) adalah data setelah tapis dan (b) adalah data 
sebelum tapis. Tidak ada perbedaan signifikan karena data geomagnet aslinya sudah bagus (tidak ada outlier).

a

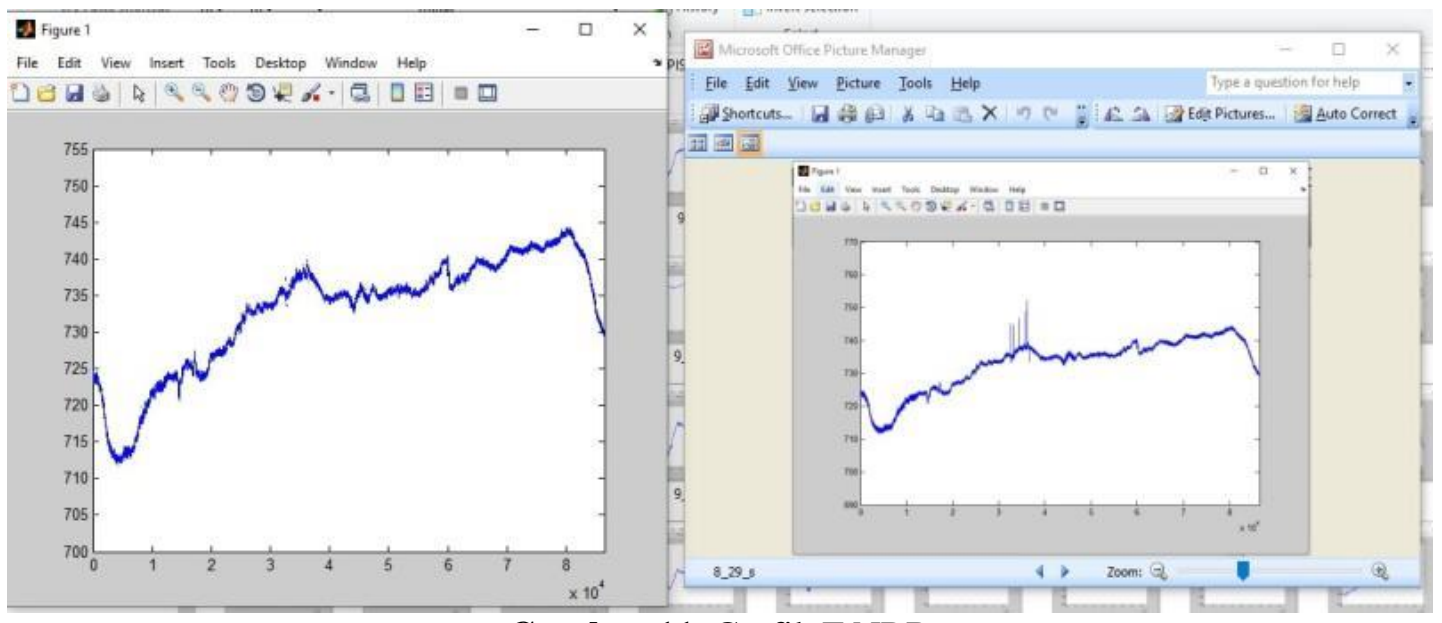

Gambar 11. Grafik F NRB

Gambar 11. menunjukkan data medan magnet total (F) di Stasiun Nurul Bayan Lombok tanggal 29 Agustus 2018, dimana (a) adalah data setelah tapis dan (b) adalah data sebelum tapis. Ada perbedaan signifikan antara keduanya karena data geomagnet aslinya terdapatoutlier sehingga banyak muncul spikes.

a

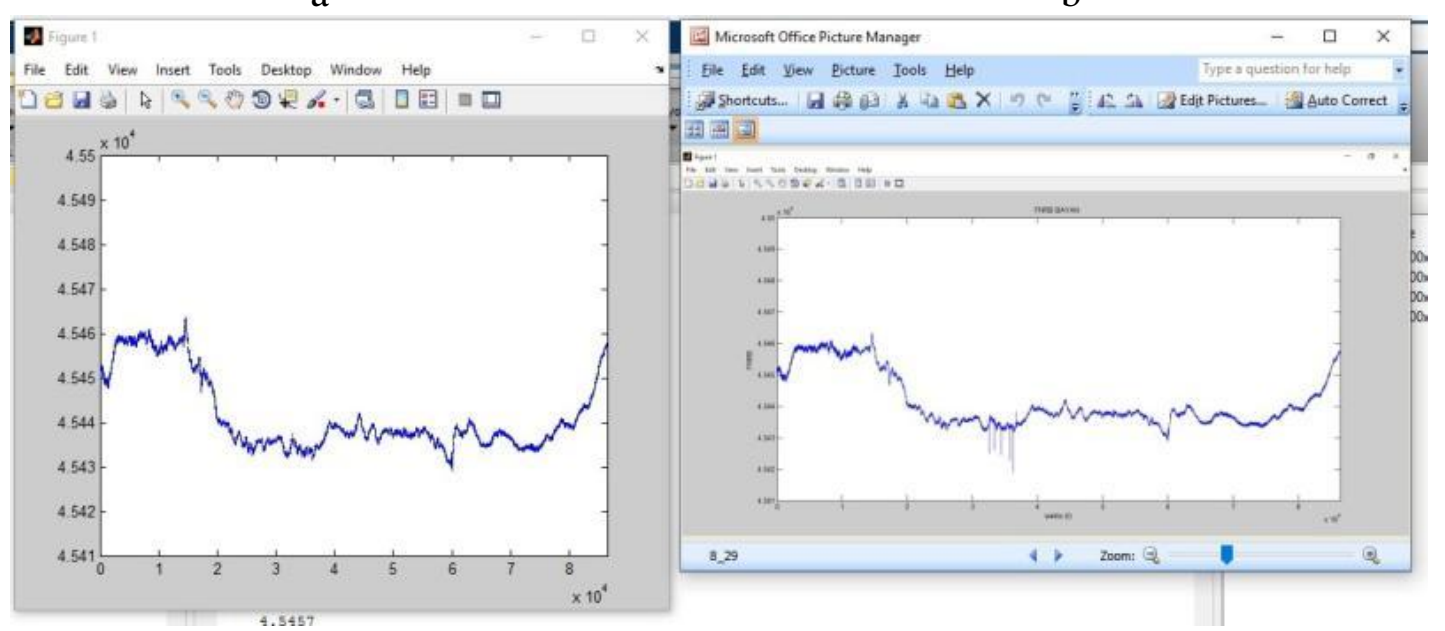

Gambar 12. Grafik Hasil Diferensiasi

Gambar 11. menunjukkan data hasil diferensiasi tanggal 29 Agustus 2018, dimana (a) adalah data setelah tapis dan (b) adalah data sebelum tapis. Ada perbedaan signifikan antara keduanya karena data geomagnet NRB aslinya terdapat outlier sehingga di hasil diferensiasi juga muncul banyak spikes.

\section{KESIMPULAN}

Hasil Diferensiasi F KDU - F NRB normalnya diantara 700 - 750 nT. Ada fenomena anomali medan magnet Bumi di wilayah Nurul Bayan Lombok yang terdeteksi selama 17 
hari di bulan Oktober 2018, yaitutanggal 11 - 13 Oktober 2018 (3 hari) dimana magnet total NRB mengalami penurunan yang signifikan sekitar 200 nT, tanggal 14- 19 Oktober 2018 (6 hari) dimana magnet total NRB mengalami kenaikan yang signifikan sekitar $300 \mathrm{nT}$, dan tanggal 20 - 27 Oktober 2018 (8 hari) dimana magnet total NRB masih belum stabil, di nilai sekitar 600 - 800 nT. Pertanda anomali sinyal ULF ini diperkirakan sebagai pertanda kejadian gempa.Dengan mengetahui karakteristik gempa bisa dijadikan sebagai kajian strategis untuk membangun sistem peringatan dini gempa bumi atau Earthquake Early Warning System (EEWS) Pulau Lombok dalam upaya mitigasi bencana berikutnya.

\section{Ucapan Terima Kasih}

Terima kasih kami sampaikan kepada LPPM Universitas Mataram yang telah memberikan dana sehingga penelitian ini berjalan dengan baik. Kemudian juga kami ucapkan terima kasih kepada PUI Geomagnetik Universitas Mataram sebagai tempat meneliti dan mengambil data primer. Berikutnya kepada Jaringan Intermagnet IAGA yang telah menyediakan data geomagnetik open access.

\section{DAFTAR PUSTAKA}

Howard, J., 2017. Computational Methods for Numerical Analysis with R. CRC Press.

Kanata, B., Zubaidah, T., Ramadhani, C., 2013. Changes of the Geomagnetic Signal Linked to Tohoku Earthquke on March 11th, 2011. International Journal of Technology, 5, 3 (SE).

Khairunnas, Irmawati, B., Zubaidah, T., Kanata, B., Aranta, A., Ratnasari, D., 2020. The Handling of Missing Data At Nurul Bayan Geomagnetic Station, Lombok. Mataram: Proceedings of International Conference on Science and Technology (ICST) 1, 255260.

Kinasih, I.P., Wiriasto, G.W., Kanata, B., Zubaidah, T., 2014. Lesser Sunda Island Earthquake Inter-Occurrence Times Distribution Modeling. International Jurnal of Technology, 3, 242-250

Mathieu, L., Jean-Baptiste, A., François H.L.R.C., 2017. Interpolation in Time Series: An Introductive. Water, 9, 796.

Saroso, S. , 2010. Penentuan Prekursor Gempa Bumi Menggunakan Data Geomagnet: Jakarta: Massma Publishing.

Zubaidah ,T., Kanata, B., Nurhandoko, BEB., Bijaksana, S., 2006. Pemantauan keberadaan anomali geomagnet ekstrem di pulau Lombok NTB: Penentuan pola variasi anomali geomagnet untuk prediksi terjadinya gempa tektonik di daerah patahan. Laporan akhir penelitian - Hibah Pekerti tahun 2006, Jurusan Elektro FT-UNRAM.

Zubaidah, T., Kanata, B., Ramadhani, C., Irmawati, B., 2013, Comprehensive Geomagnetic Signal Processings for Sucessful Earthquake Prediction. Yogyakarta: Proceeding of the 13th Quality in Reseacrh (QiR) 2013.

Zubaidah, T., Korte, M. Mandea. M., Hamoudi, M., 2014. New insights into regional tectonics of the Sunda-Banda Arcs region from integrated magnetic and gravity modelling. Journal of Asian Earth Sciences, 80, 172-184. 